DOI: 10.22559/folklor.1042

folklor/edebiyat, cilt: 25 , sayı: 100, 2019/4

\title{
Sözlü Türk Külttürünün Yaşaması ve Aktarımında Hataylı Ozanların Rolü
}

\section{The Role of Incidental Scenes in the Living and Transfer of Oral}

\author{
Ali Yakıcı* \\ Berrin Saritunç**
}

Öz

Ünlü Türk romancısı Cengiz Dağcı, bir yazısında “anayurt dediğin dildir aslında..." biçiminde bir ifadede bulunur. Ünlü yazarın belirttiği gibi coğrafyaların vatan haline dönüşmesinde dilin etkisinin önemli olduğu görülmektedir. Dilin canlı olarak yaşadığı/ yaşatıldığı kurumlardan bir de halk ozanlığı/ âşıklık geleneğidir. Yüzlerce yıl bulunduğu coğrafyada yaşayan insanların dili, gönlü ve yükselen sesi olan ozanlar Türkçeyle doğumdan ölüme kadarki süre içinde bulunduğu insanının yaşadıklarını şiirleştirmiş, böylece tarihe tanıklık ederken sözlü kültürle birlikte eserlerini oluşturduğu Türkçenin de yaşamasına ve gelecek kuşaklara aktarılmasına büyük ölçüde yardımcı olmuştur. Bu bakımdan bu bildiriyle Hataylı ozanların yaşadıkları dönemde bulundukları bölgeye tanıklık edecek eserler oluştururken bunlarla Türk kültürel kimliğinin yaşatılması ve geleceğe aktarılmasında oynadıkları rolün fark edilmesi amaçlanmaktadır.

Bu çalışmayla, Hatay'da Türk kültür varlığının yaşaması ve Hatay'ın ebedi bir Türk vatanı olarak devamında etkili olan ve gün ışına çıkmamış sözlü kültür ürünleri ela alınıp işlenecektir. Bunlar içinde başta Kırıkhan ilçesi ve özellikle Ceylanlı Köyü ozanları olmak üzere Sefil Molla, Sefil Hasan, Sefil Ahmet gibi kimileri Halep’te

Prof.Dr., Gazi Üniversitesi Edebiyat Fakültesi, yakici@gazi.edu.tr. ORCID ID 0000000194617324.

** Öğr. Gör. Uludağ Üniversitesi Rektörlük Türk Dili ve Edebiyatı Öğr.Gör., bsaritunc@uludag.edu.tr. ORCID ID 0000000186626562 . 
ikamet etmiş oradan Hatay'a gelmiş olan âşıkların yazmalarda yer alan şiirlerinin Hatay'da bir kültür hazinesinin oluşumundaki rolü ve tesiri tartışılacaktır.

Anahtar sözcükler: Hatay'da kültürel miras, Türk sözlü geleneği, halk ozanlart, dil ve kültür aktarımı

\begin{abstract}
:
He famous Turkish novelist Cengiz Dağc1, in one of his articles, says Dağ the language you call homeland is actually Dağ c1. As noted by the famous author, it is seen that the effect of language is important in transforming geographies into homeland. It is a folk poet / minstrelsy tradition from the institutions where the language lives / lives alive. The language of the people who lived in the geography of the region for hundreds of years, hearts and rising voice poets Turkish poetry, from birth to death of the time of the people lived in poetry, so that the oral culture together with the oral culture of his work has helped greatly to transfer and future generations of Turkish. In this respect, with this declaration, it is aimed to recognize the role played by the bardans of Hatay in the period they live and create the works that will be witness to the region where they live and to play the Turkish cultural identity and to transfer them to the future.

With this study, the existence of Turkish cultural assets in Hatay and the effective and effective culture of Hatay as an eternal Turkish homeland will be taken over and will be processed. Among them, especially the Kirikhan district and especially Ceylanli village poets, such as the Miser Molla, Sefil Hasan, Sefil Ahmet, some of whom lived in Aleppo from there to Hatay, the poems of the lovers in the manuscripts will be discussed in the formation of a cultural treasure in Hatay.
\end{abstract}

Keywords: Cultural heritage in Hatay, Turkish oral tradition, folk poets, language and culture transfer

Dilin, kültürün, milli bilincin ve milli ruhun oluşmasında ozanların etki ve katkısı büyüktür. Ozanlar, Türk dili ve kültürünün doğuşunda, gelişmesinde ve nesilden nesle aktarılarak hayatını devam ettirmesinde birinci derecede önem arz etmektedir. Türkçe, kimi araştırmacılara göre Milattan önce kırkıncı, kimilerine göre de bin on ikinci asırlarda sözlü olarak metinlerini oluşturmuştur. Bu ilk metinler manzumdur ve enstrüman eşliğinde bir müzik parçası olarak icra edilmeleri sonucunda elde edilmiştir. Bu manzum metinlerin ilk icracıları ise ozanlardır. Araştırmacıların genel kanaatine göre edebiyat-müzik sanatçılarının çeşitli tören ve toplantılarda besteli olarak icra ettikleri enstrüman eşliğinde söylenen bu manzum parçalar Türk edebiyatının ilk metinlerini oluşturmuştur. Bu bakımdan ozanlık geleneği, başlangıcından günümüze Türk kültür ve edebiyatının oluşması ve gelişmesinde önem ve kıymeti bilinen kültür dinamiklerinin başında gelmektedir.

Bu konuda edebiyat tarihçisi Fuat Köprülü şu bilgilere yer vermektedir:

Tarihin kaydedemeyeceği kadar eski zamanlardan beri millet hayatı yaşamış, çeşitli medeniyet dairelerine girmiş, dilini yazmış bir millet olan Türkler arasında daha yazı yayllmadan önce mevcut bulunan milli-sözlü edebiyat, dilin ilk teşekkü- 
lünden beri canlı bulunduğu gibi yazının yayılmasından sonra da devam etmiştir. Türkler muhtelif medeniyet dairelerine girdikleri daha sonraki dönemlerde de bu gelenek yine kuvvetle yaşamasinı sürdürmüştür.

En eski Türk şairleri; Tunguzların şaman, Moğol ve Boryatların bu/buğu, Yakutların oyun, Altay Türklerinin kam, Samoyetlerin tadıbey, Finlilerin tetoya, Kırgızların baksı/ bakşı, Oğuzların ozan adını verdikleri şairlerdir (Köprülü, 1986: 57).

Kuraklık, iç savaş vb. nedenlerle gerçekleştirilen kitlesel göçler, kitlelerin göç ettikleri coğrafyalarda kültürel ürün ve olguları yeni coğrafyalara taşımalarında başlıca etken olmuştur. Bulundukları coğrafyadan başka coğrafyalara göç eden toplulukların beraberinde taşıdıkları hazinelerin başında sözlü kültür ürünleri gelmektedir. Çünkü bu ürünler, kişilerin dillerinin oluşturduğu belleklerde taşındığı için göç sırasında ayrı zahmet ve külfete yol açmamaktadır. Göçler yoluyla yeni coğrafyalara taşınan bu ürünlerin başında ozanlara ait şiirler, destanlar, sagular, savlar, hikâyeler, masallar, efsaneler ve ana malzemesi dil olan diğer ürünler gelmektedir. Dolayısıyla göçlerle taşınan ana malzemenin dil olduğu görülmektedir (Yakıc1, 2009: 3).

Göç ve diğer sebeplerle yeni coğrafyaların vatan haline dönüşmesi ve anayurt oluşunda dilin çok büyük rolü vardır. Çünkü, kültürel kimliğin oluşumunda birinci derecede etkili olan dildir. Diller sıradan bir iletişim aracı olarak kullanıldıklarında kalıcılıklarını sürdüremezler. Eğer, şairler, yazarlar, sanatçılar, edebiyatçılar, tarihçiler, siyasetçiler, hukukçular, mühendisler, antropologlar, çalışmalarını kendi diliyle yapmaz, her alanda kendi diliyle eserler bırakmazlarsa; "söz uçar yazı kalır" özlü sözünde olduğu gibi dilleri yok olur. Türkçe bu bakımdan şanslı dillerden biridir. Çünkü yazının kullanılmadığı dönemlerde sözlü gelenek içinde yetişen ozanlar Türk diliyle eserler üretmişler, yazının kullanılmaya başladığı döneme kadar ve sonrasında da birçok sözlü ürün ve eserin meydana gelmesini sağlamışlardır.

Ozanların diliyle Milattan önceki yıllarda oluşturulup aktarılan ve günümüze kadar ulaşan bu eserlerin başında inanç ağırlıklı Yaratılış destanları görülmektedir. Devamında ise; Saka/İskit destanları; Alp Er Tunga ve Şu destanları, Hun-Oğuz destanları; Oğuz Kağan ve Atilla destanları, Göktürk destanları; Bozkurt ve Ergenekon destanları, Uygur Türklerinin destanları; Türeyiş ve Göç destanları yer almaktadır (Atsız, 1992: 31-80; Sakaoğlu-Duymaz, 2002: 167-230).

Yazının Türkler tarafından kullanıldığı var sayılan 5. asırdan bu yana ozanların Türkçe yazdığı birçok ürünün günümüze kadar ulaştığı bilinmektedir. Göktürk Yazıtlarındaki metinleri oluşturan kişilerden biri olan Yolluğ Tigin'in, adı bilinen ilk ozan olarak kabul edilebileceğini belirten kimi bilim adamları bulunmaktadır (Yakıcı, 2009: XI).

Uygurlar döneminde ve özellikle 8-9. asırlarda yazıya aktarılan şiirleri günümüze kadar ulaşan kimi ozanların adları bilinmektedir. Bunlardan bazıları; Aprinçur Tigin, Kül Tarkan, Sinkgu Seli Tutung, Kalım Keyşi, Asiya Tutung, Çisuya Tutung, Pratyaya Şiri, Çu-Çu ve KiKi'dir (Arat, 1986: XX-XXII).

Bu ozanlara ait olduğu bilinen ilk şiirlerin türleri ise şu şekilde sıralanabilir: Koşug, kojan, takşut, takmak, ır, yır, cır, küg, şlok, padak, padaka, kav, kavi, baş, başik (Arat, 1986: XI-XIX). 
Atayurt olarak kabul ettikleri vatanlarından Anayurt olarak belirginleştirdikleri vatanlarına gelirken belleklerinde sözlü kültür ürünlerini ve ozanlık geleneğini de yeni yurtlarına taşımışlardır. Ozanlar, sözlü kültürün belleklerde yeni coğrafyalara taşınma ve aktarılmasını iki önemli göç yoluyla gerçekleştirmişlerdir. Bunlardan ilki Büyük Hun Devleti'nin dağılmasından sonra Miladın ilk asırlarında Aral Gölü, Hazar Denizi ve Karadeniz'in kuzeyinden Avrupa içlerine yapılan göçtür (Köprülü, 1980: 8-10).

Ünlü coğrafyacı Batlamyus, bu göçün MS 2. yüzyıla kadar uzandığını, çünkü aynı yüzyılda Hun Türklerinin Karadeniz'in kuzeyinde Azak Deniziyle Ten ve Özi nehirleri arasında yaşandığını belirtmektedir. Bu durum ise göçebe Türklerin bu tarihe kadar Uralları aşarak Tuna boylarına doğru akınlar düzenleyip geri çekildiklerini ve bu akınlarla büyük göçler için bir çeşit keşif faaliyetinde bulunduklarını belirginleştirmektedir (Yıldırım, 1998: 183).

Kuzeyden Avrupa içlerine, Adriyatik kıyılarına kadar uzanan asıl göçler MS IV. asırda Atilla'yla gerçekleşmiştir. Dolayısıyla ozanlık geleneğinin Orta Asya merkezli Orta Asya coğrafyasından göç yoluyla Avrupa'ya taşınması ya da orada bulunan benzer geleneklerin güçlenmesine yardımcı olunduğuna dair bilinen ilk örnekleri Atilla döneminde verilmiştir. Atilla'yla birlikte bulundukları coğrafyadan göç ederek Avrupa içlerine kadar gelen ozanlar, başta o günkü Avrupa ulusları olmak üzere özellikle Almanların ve çevre kültürlerin geleneklerine tesir etmiş, o kültürlerde ozan tipi şiir söyleme geleneğinin oluşmasında etkili olmuşlardır. Alman Nibelungen destanları, Dietrich ve diğer metinler bunun açık örneğini/ örneklerini oluşturmaktadır (Helmut de Boor, 1981: 5-60).

Türklerin 10. yüzyıldan itibaren yeni dinleri İslamiyet'le buluşup tanıştıkları, din olarak İslam'ı kabul ettikleri, böylece İslam inancıyla birleşerek yeni bir güç kazanan ozanlık geleneği; Ahmet Yeseviler, Yunus Emreler, Dede Korkutlar, Köroğlular, Âşık Ömerler, Âşık Garipler, Ercişli Emrahlar, Karacaoğlanlar ve daha sonraki asırlarda yüzlercesi yetişen ozanlarla önemini korumuştur. Adları binlerle ifade edilebilecek olan bu ozanlar, Türk dilinde eserler vererek hem Türk kültür hazinesinin zenginleşmesine hem de Türk kimliğini oluşturan ana unsur olan Türkçenin yediden yetmişe aynı coğrafyayı paylaşan insanların belleklerinde ve dillerinde yaşamasına /yaşatılmasına katkı sağlamışlardır. Bu durum Hatay ili örneğinde de belirgin olarak görülmektedir.

Karadeniz'in kuzeyinden Avrupa içlerine taşınan bu gelenek, bir başka yoldan da Orta Doğu, Yakın Doğu ve Balkanlara ulaşmıştır. Orta Asya merkezli yurtlarından güney ve batı yönünde göç eden Oğuz gruplarından bir bölümü, Hazar'ın batısında, bugünkü Azerbaycan coğrafyasında yurt tutmuş, bir bölümü de bugünkü Türkmenistan, İran, Irak, Suriye, Türkiye vb. coğrafyalara yerleşmiştir. Oğuzların bir bölümü de Karadeniz'in güneyinden Balkanlara ulaşmış, o coğrafyalarda yurt tutmuş, ozanlık geleneğinin yerleştikleri bu yeni coğrafyalarda yeniden filizlenip gelişmesine ve kültürel mirasa dönüşmesine vesile olmuşlardır (Yakıcı, 2009: 14).

İşte bu ikinci göç dalgası ozanlık geleneğinin Hatay ve çevresinde yerleşip gelişmesinde önemli rol oynamıştır.

Fuat Köprülü, Batılı kaynaklardan hareketle Anadolu'da ve dolayısıyla Hatay ve çevresinde güçlü bir ozanlık geleneğinin oluşmasını Selçuklu, Memluk ve Celayirli yönetimlerindeki güçlü ozanlık geleneği ve ozanların varlığına bağlamaktadır: 
İslamiyet'in kabulünden önce ve sonra Türkler arasında bulunduğunu kesin olarak gösterdiğimiz halk şair-musıkişinaslarının, daha Selçuklular devrinden başlayarak XIV-XV. astrlarda Anadolu'da mevcudiyeti pek tabiidir. XIII. astrda Anadolu Selçuklularının ordularında gördüğümüz ozanları, Mısır Memlukleri devletinde hükümdarların tantanalı alaylarında, Türkleşmiş bir Moğol hanedanı olan Celayirlilerde, hatta XV. asırda Anadolu Beylerinin saraylarında da görüyoruz. Genellikle Oğuz destanlart söyleyen bu ozanların XIV ve XV. astrlarda Osmanlı ordularında ve halk arasında, Hatay ve Anadolu'nun başka yerlerinde olduğu gibi halk şair ve musıkişinaslarının bulunduğu muhakkaktır (Köprülü, 1986:161-162).

Evliya Çelebi, Türklerin Orta Asya'daki Atayurtlarından anayurtları olan Orta Doğu ve Türkiye'ye başlattıkları ikinci göç dalgasıyla gelip yerleştiği kuvvetle muhtemel olan Türkçeyi ve dolayısıyla malzemesi Türk dili olan ozanlık geleneğinin Hatay'daki varlığını çok daha önceki asırlara taşımaktadır. Çelebi kültür tarihçilerinin verdikleri bilgiler ve anlatılardan hareketle bu bölgede Türkçenin ve dolayısıyla ozanlık geleneğinin varlığını Nuh'un oğlu Yafes'e kadar götürmektedir.

Türkçenin bir dil olarak yaşamasında, Türk dili ve kültürünün asırlar ötesine aktarılmasında ozanların/ âşıkların önemli rollerinin olduğu bilinmektedir. Hatay bu bakımdan çok daha şanslı görünmektedir. Çünkü Evliya Çelebi'nin verdiği bilgiye göre Nuh peygamberin oğlu Yafes, Tufan'dan sonra Antakya kalesini onararak buraya yerleşmiş, Yafes'in oğlu Türk burada doğmuş ve çoluk çocuk burada çoğalarak yeniden dünyaya yayılmışlardır (Evliya Çelebi, 1982: 17).

Ünlü Seyyah, Yafes'le ilgili bu görüşünü daha da belirginleştirerek Arapça, Farsça, Türkçe ve Türkçeye bağlı Tatar lehçesinin nasıl ortaya çıktığına dair Seyahatnâme'de şu açıklayıc1 bilgilere yer vermektedir:

Tarihçilerin sözüne göre Hazreti Nuh tufanından sonra üç yüz yıl daha yaşayıp üç oğlu oldu. Birisi Ham'dır ki, kara Araplar, firavunlar bunun soyundandır. Birisi Sam'dır ki Arap ve Acem cümle peygamberler onun temiz kanından dünyaya gelmişlerdir. Biri de Yafes 'tir. Türk ve Tatarlar bundan oldu (Evliya Çelebi, 1982: 50).

Hatay ve çevresinin de içinde yer aldığı Anadolu coğrafyasına ozanlık geleneğinin taşınmasında Dede Korkut'un önemli bir yerinin olduğu muhakkaktır.

Köprülü'ye göre Dede Korkut Kitabı, ozanın mahiyeti ve Oğuz aşiretleri arasındaki yeri hakkında çok açık bilgiler vermektedir. Ozanlar, Oğuz toplulukları arasında özel bir sınıf oluşturmaktadır. Bunlar ellerinde kopuzlarıyla ilden ile, obadan obaya gezerler, düğünlerde, ziyafetlerde bulunurlar, kopuzlarıyla eski Oğuz destanları, Dede Korkut hikayeleri söylerler; yeni hadiselerle ilgili yeni yeni şiirler tanzim ederler, zenginler de onlara bazen sırtındaki elbiseyi çıkarıp verir, koyunlar, keçiler ihsan ederlerdi. Bununla birlikte Dede Korkut Kitabı'nda ozanların daha eski dönemlerdeki önemlerine dair de önemli bilgiler bulunmaktadır. Ozanların piri olan dede Korkut'a verilen değer o kadar büyüktür ki, ona mensup olduğu için kopuzun bile yarı kutsal sayılmasını sağlamaktadır. Çevik dilli, yüksek sesli, halk ananelerini ve hikmetlerini taşıyan ozan, daha eski dönemlerde Oğuzlar arasında yarı kutsal bir varlık olarak kabul edilmekteydi. Edebi gelişmelerin gidişatı Oğuzlar arasında da aynı akışı takip etti ve ozanlar eski kutsallıklarını kaybetmekle birlikte Oğuz aşiretleri arasında özel bir 
sanatçı sınıfı olarak yaşamaya devam ettiler ve önemlerini korudular. XV. yüzyıldan itibaren de yaygın olarak âşık adını aldılar (Köprülü, 1986: 139-140).

Türk dünyası olarak kabul edilen Kazakistan'dan Azerbaycan'a, Aral'dan İran'a, Irak ve Suriye'ye, Hazar'dan Türkiye'ye büyük bir coğrafyada Dede Korkut tesiri görülmektedir. Dış Oğuz'u Bozoklar oluştururken özellikle İç Oğuz'u oluşturan Üçokların, Dede Korkut'taki hanlar hanı Bayındır Han'ın tesirinin Hatay'ı da içine alan büyük bir coğrafyada hüküm sürdüğü, dolayısıyla bu coğrafyada Dede Korkut sanatı olan güçlü bir ozanlık geleneğinin var olduğu bilinmektedir (Ergin, 2009: 47-53).

Cezayir'den İskenderun'a uzanan çok büyük bir coğrafyada Akdenizli halk şairlerinin varlığı ve güçlü bir etkilerinin olduğu belirgindir (Elçin, 1988).

Akdeniz Bölgesinde yer alan Hatay ve çevresi de ozanlık geleneğinin yaşadığı/ yaşatıldığg önemli bölgelerdendir. Uzun yıllar Selçuklu yönetiminde ve sosyal, siyasal ve kültürel bakımdan etkisinde kalan Hatay ve çevresinde güçlü bir ozanlık/ âşıklık geleneğinin teşekkül etmesi çok doğaldır. Türkiye sahasında âşıklık geleneğinin müstakil olarak oluşmaya başladığı ilk asırlarda Hatay ve çevresinde ozanların ve ozanlar etrafında oluşan güçlü bir ozanlık geleneğinin varlığı bilinmektedir.

Türkiye'nin kültür atlasına bakıldığında ozanların bazı bölgelerde yoğunlaştığı, bu bölgelerde geleneğin bir okula dönüştüğü görülmektedir. Bu illerden biri de Ceylanlı Köyü, Dörtyol'u, İskenderun'u, Reyhanlı'sı, Kırıkhan ve Belen'iyle Hatay ilidir.

Türkiye sahasında âşıklık geleneğinin oluştuğu 16. Yüzyılda Hatay ve çevresinde varlığı bilinen/ görülen ozanların başında Âşık Garip ve Karacaoğlan gelmektedir.

Âşık Garip, 16. yüzyılda, döneminde ozanlık geleneğinin güçlü bir biçimde yaşadığı/ yaşatıldığı Kars, Tiflis, Tebriz gibi Türk kültür merkezlerinden Halep'e gelmiş, burada sanatını icra ettiği bir âşık kahvesi açarak bu mekânın bir gelenek okuluna dönüşmesini sağlamıştır. Âşık Garib'in Halep merkezli olarak geleneği icra etmesi, ozanlık geleneğinin Halep'te olduğu kadar yakın çevresinde bulunan Hatay’da gelişmesinde de etkili olmuştur:

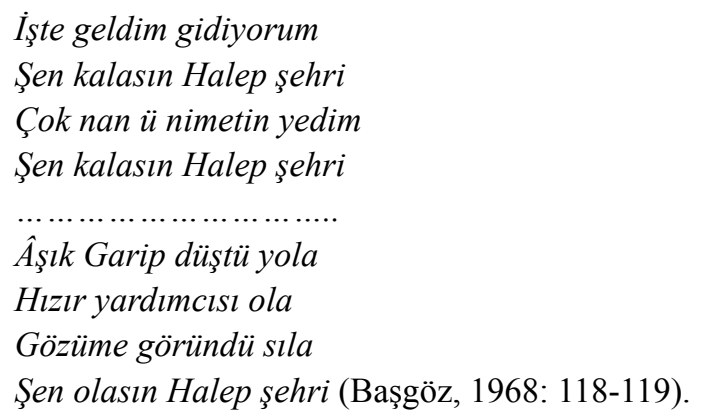

Âşık Garip ozanlık sanatını Halep merkezli olarak etkili kılarken Karacaoğlan Hatay’ın da içinde yer aldığı güney illerini adım adım gezerek sanatını icra etmiş, türküler söylemiş, ozanlık geleneğinin bu bölgede kök salmasına öncülük etmiştir. Karacaoğlan Hatay merkezli bu bölgede Adana'dan Münbiç, Halep, Hama, Humus ve Şam'a kadar uzanan coğrafyada at koşturmuş, sazıyla sözüyle yöre insanıyla buluşmuştur. 
Âşık der ki ne olacak

Haleb'i Osmanli alacak

Bu dünya mamur olacak

Dă̆ı taşa katar bir gün (Ergun, 1948: 239)

Gönül arzuluyor Antep elini

Şol Kemnun Gediği beli görünür

Evvel bahar yaz ayları doğunca

Coşar Balıksuyu seli görünür

Karacaoğlan der ki Ergene köyü

Beşdeli'den akar Haleb 'in suyu

Tilbaşar elinde şol Ekiz Kuyu

Edepli erkanlı yolu görünür (Sakaoğlu, 2004:628)

Bitti m'ola Şam ilinin hurması

Gitti m'ola ala gözün sürmesi

Hama'nın Humus'un telli turnası

Turna yârin selam saldı gel diye (Karaer, 1980: 107)

Belli belli bağlarının boranı

Çift çift olmuş çöllerinin ceranı

Sana derim sana Munbuç viranı

Çarşında çağrışan tellallar hani

Munbuç'un kapısı altın tokalı

Kimse yaptırmamış felek yı kalı

Ulu şadırvanı çatal birkeli

Kastelinde abdest alanlar hani (Başgöz, 1977: 79)

Ak kuğular sökün etti yurdundan

Koç yiğitler yatamıyor derdinden

Sabah namazında Belen ardından

Saydım altı güzel indi pınara (Başgöz, 1977: 59) 
Hataylı ozanların ağıtları, destanları, koşmaları ve türküleriyle yer aldığı kaynakların başında Ali Rıza Yalman (Yalkın)'ın iki kitaptan oluşan Cenupta Türkmen Oymakları adlı eseri gelmektedir. Yalman, Hatay'ın da içinde bulunduğu büyük bir coğrafyada, İlbeyli'den Beydili'ye, Bayat'tan Avşar'a birçok Türkmen aşiretini gelenek-görenekleri ve edebiyatlarıyla derlemiş, incelemiş, edebi metinlerin yanı sıra o metinlerin yaratıcıları olan ozanlara da itibarlı bir yer vermiştir.

Elbeyli Hasan Ağa'dan:

\section{Felek ondurmadı bizim yerimiz}

Bir araya gelemedi dördümüz

Munbuç bizim fermanlı bir şarımız

Çöller bizim ata dede yurdumuz

Hey ă̆alar Kara Dă̆ın eteği

Dă̆llsın mı Elbeyli'nin peteği

Vezirler kuşă̆l, arslan yatağ

Obama da malum olsun halimiz

(Yalman, 1977:95).

Hatay'da geleneğin sürdürülmesinde etkili olan mekân ve ortamlardan biri Ceylanlı Köyü’dür. Ceylanlı Köyü âşıklık geleneği üzerine birkaç farklı akademik çalışma yapılmıştır. Bu çalışmalardan biri Gazi Üniversitesinde yüksek lisans tezi olarak Sedat Bahadır tarafından yapılmıştır. Daha sonra kitaplaştırılan bu çalışmada adı geçen köyde yaşayan ve geleneği sürdüren dört âşığın hayatı, sanatı ve türkülerine yer verilmiştir. Bu âşıklar; Kul Abdullah, Âşık Hasan, Âşık Hacı ve Âşık Ali'dir.

Ceylanlı Köyü ozanları mukayeseli olarak incelendiğinde hem dil hem konu hem de idealler bakımından benzerlikler görülmektedir. Birer birer bakıldığında bu âşıkların aşkları, sevgileri farklı olmakla birlikte tamamının birleştiği bir sevgi var ki o da yurt, millet ve dil sevgisi; Türkçe Türklük sevdasıdır.

Ceylanlı Köyü âşıkları sıklıkla Hatay’ın bir Türk yurdu olduğunu vurgulamış, bu ili sosyal, siyasal ve kültürel yönleriyle şiirlerine konu olarak almış ve işlemişlerdir:

Yüksek beyler şöyle demeğe karşı

Methetmek istiyor dilimiz bizim

Türkiye'de bir yaratmış Yaradan

Hatay vilayeti ilimiz bizim

Ceylanlı köyüdür bizim köyümüz

Yüksek sarp kayalı yüce dă̆ımız

Kırıkhan'ın Kaymakamı Beyimiz

Has bahçe çiçeği gülümüz bizim 
Antakiye vilayetler halisi

Çok edepli memurları polisi

Vali paşa cümlesinin ulusu

Yüksek adaletli valimiz bizim

Vali Paşam bu Hatay'a bir geldi

Evveli gelseydi biraz geç kaldı

Siz gelince insan medeni oldu

Kalmadı bir çapkın dölümüz bizim

Asşı Ali'm bunu demekte söyler

Dinleyen beyler de mütalâ eyler

A ̆gzınnan çıkanı cereyana bağlar

Sabahtan dil verir telimiz bizim (Bahadır, 2016:213-214)

Ceylanlı Köyünün yetiştirdiği önemli ozanlardan biri de Sefil Molla'dır. Hatay'da geleneğin güçlü temsilcilerinden olan Sefil Molla'nın ömrü Halep, Hama, Humus ve Kırıkhan arasında geçmiştir. Methiyeleri, taşlamaları ve mektupları meşhurdur.

Vasfinı söyleşir Antaki, Halep

Çarkı bozulunca döner mi dolap

Asil hanedansin değilsin celep

Paktır aslin, soyun, cinsin Avc'ağa (Konyalı: 256)

Yaşayan Çukurovalı âşıklar ve geleneğe tabi halk şairleri üzerine yapılan çalışmaya bakıldığında; içlerinde Yayladă̆ı'ndan Âşık Ali Yemini ile Kırıkhan'dan Âşık Mehmet Kadersiz ve Halit Toklucuoğlu'na yer verdiği görülmektedir (Ekmekçi, 2006:577-578).

19-20. asırlarda Hatay'da ozanlık geleneğinin halkasını oluşturan önemli bir yapının olduğu görülmektedir. İşte bu yapı içinde yetişen ozanlar, sözlü şiir geleneğine, Türk müziğine, Türk edebiyatına, Türk kültürüne önemli eserler kazandırmış, bu coğrafyada Türk kültürel kimliğinin yaşamasına ve sözlü Türk kültür mirasının günümüze aktarılmasına önemli ölçüde vesile olmuşlardır. Hatay'da yaşamış ve yaşamakta olan ve geleneğin yaşatılmasını sağlayan onlarca ozan bulunmaktadır. Hüseyin Kürşat Türkan, Âşık Duran Bebek’i ele aldığı çalışmasının Giriş kısmında kimi Hataylı ozanlardan da söz etmiş̧tir. Bunların adları kitapta yer alış sırasıyla şöyledir: Âşık Mehmet Askerden, Âşıı Ali Avcı, Âşık Bekir Cila, Âşık Hilmi Kınalı, Âşık Mehmet Köse, Âşık Mustafa Cengiz, Âşık Ömer Bozdoğan, Âşık Mehmet Doğan Yusufoğlu, Âşıı Beyazıd Bestami Yaran, Âşık Emin Can, Âşık Kıraç Ata (Ekrem 
Kıraç), Âşık Sefil Ali, İlyas Aydın Hacı, Muhittin Alaca, Mustafa Halis (Halis Usta), Sefil Ahmet, Âşık Mustafa İncedil, Sefil Molla, Âşık Kara Mustafa, Âşık Meryem, Âşık Yusuf Doğruer, Âşık İbrahim Er, Kul Mehmet, Âşık Hacı, Âşık Avcı Osman, Âşık Mazlum, Ömer Kasar, Âşık Muştuk Paşa, Âşık Ömer Sayıl, Âşık Hasan, Âşık Kul Celal, Âşık Kamil Sarıteş, Kul Selim ve Âşık Duran Bebek (Türkan, 2017: 27-175).

Yukarda adları verilmiş olan Hataylı âşıkların önemli bir bölümü Kırıkhan ilçesinden, onlardan önemli bir bölümü de Ceylanlı Köyündendir. Yukarda adı belirtilmemiş Hataylı bir ozan daha vardır ki o da Kırıkhan'ın Saylak Köyünden Yahya Şükrü Lelik’tir.

\section{Selam olsun dedem yurdu köyüme}

Yă̆mur yă̆dı dereleri coştu mu?

Şimdi cennet gibi bizim oralar

İğde koktu gonca güller açtı mı? (Yakıc1, 2005: 50)

\section{Sonuç}

Ozanlık geleneği, başlangıcından günümüze Türk kültür ve edebiyatının oluşumunda önem ve kıymeti bilinen kültür miraslarından biridir. Göç ve diğer sebeplerle yeni coğrafyaların vatan haline dönüşmesi ve anayurt oluşunda dilin çok büyük rolü vardır. Kültürel kimliğin oluşumunda birinci derecede etkili olan dildir. Diller sıradan bir iletişim aracı olarak kullanıldıklarında kalıcılıklarını sürdüremezler. Eğer, şairler, yazarlar, sanatçılar, edebiyatçılar, tarihçiler, siyasetçiler, hukukçular, mühendisler, antropologlar, çalışmalarını kendi diliyle yapmaz, her alanda kendi diliyle eserler bırakmazlarsa; "söz uçar yazı kalır" özlü sözünde olduğu gibi dilleri yok olur. Türkçe bu bakımdan şanslı dillerden biridir. Çünkü yazının kullanılmadığı dönemlerde sözlü gelenek içinde yetişen ozanlar Türk diliyle eserler üretmişler, yazının kullanılmaya başladığı döneme kadar ve sonrasında birçok sözlü ürün ve eserin meydana gelmesini sağlamışlardır. Ozanların diliyle Milattan önceki yıllarda oluşturulup aktarılan ve günümüze kadar ulaşan bu eserlere örnek olarak Yaratılış destanları, Alp Er Tunga Destanı, Oğuz Kağan vd. örnek olarak verilebilir.

Yazının Türkler tarafından kullanıldığı bilinen 5. asırdan günümüze ozanların Türkçe yazdığı birçok ürünün günümüze kadar ulaştığı bilinmektedir. Göktürk Yazıtlarındaki bilinen ilk Türkçe yazılı metinleri oluşturan kişilerden bir olan Yolluğ Tigin'in de bir ozan olduğunu belirten kimi bilim adamları bulunmaktadır. 8-9. asırlarda yazıya aktardıkları şiirleri günümüze kadar ulaşan ozanlar mevcuttur. Bunlardan bazılarının adları şu şekilde sıralanabilir: Aprinçur Tigin, Kul Tarkan, Kalım Keyşi, Asiya Tutung, Çisuya Tutung, Çi-Çi, Ki-Ki vd.

Atayurt olarak kabul ettikleri vatanlarından Anayurt olarak belirginleştirdikleri vatanlarına gelirken belleklerinde sözlü kültür ürünlerini ve ozanlık geleneğini de yeni yurtlarına taşımışlardır. İslam inancıyla birleşerek yeni bir güç kazanan ozanlık geleneği Ahmet Yeseviler, Yunus Emre'ler, Dede Korkutlar, Köroğlular, Âşık Ömerler, Âşık Garipler, Ercişli Emrahlar, Karacaoğlanlar ve daha sonraki asırlarda yüzlercesi yetişen ozanlarla önemini korumuştur. Adları binlerle ifade edilebilecek olan bu ozanlar, Türk dilinde eserler vererek hem Türk kül- 
tür hazinesinin zenginleşmesine hem de Türk kimliğini oluşturan ana unsur olan Türkçenin yediden yetmişe aynı coğrafyayı paylaşan insanların belleklerinde ve dillerinde yaşamasına / yaşatılmasına katkı sağlamışlardır.

Coğrafyaların vatan haline dönüşmesinde dilin etkisinin önemli olduğu bilinmektedir. Dilin canlı olarak yaşadığı/ yaşatıldığı kurumlardan biri de halk ozanlığı/ âşıklık geleneğidir. Yüzlerce yıl bulunduğu coğrafyada yaşayan insanların dili, gönlü ve yükselen sesi olan ozanlar Türkçeyle doğumdan ölüme kadarki süre içinde bulunduğu toplumun insanının yaşadıklarını şiirleştirmiş, böylece hem tarihe tanıklık edecek belge ve bilgilerin kalıcılığını sağlamış hem de eserlerini oluşturduğu dil olan Türkçenin daha güçlü biçimde yaşamasına ve gelecek kuşaklara aktarılmasına büyük ölçüde yardımcı olmuştur. Aynı işlevsel yaklaşım Hataylı ozanlar için de geçerlidir. Hataylı ozanlar da yaşadıkları dönemde bulundukları bölgenin kültürel zenginliğine katkı sağlayıp kültürel zenginliğini gelecek nesillere aktaracak eserler oluştururken bunlarla Türk kimliğinin yaşatılması ve geleceğe aktarılmasında önemli görevler üstlenmişlerdir.

Hatay ozanlık geleneği içinde tespit edilen 60 kadar ozanın şiirlerine bakıldığında Hatay’da Türk kültürel varlığının yaşaması ve Hatay’ın ebedi bir Türk vatanı olarak devamında etkili olan/ olacak birçok esere içinde yer verdiği görülmektedir.

Âşıklık geleneğinin etkili ve güçlü olduğu bölgelerin varlığını belirleyen Türkiye atlasına bakıldığında; geleneğin önemli merkezlerinden Erzurum, Kars, Konya, Kastamonu, İstanbul, Artvin, Ardahan, Osmaniye, Adana gibi Hatay’ın da ayrıcalıklı bir yerinin olduğu fark edilecektir. Bunda sanatçıların dilindeki temiz Türkçenin, kendine özgü sanat yapısı ve Ceylanlı gibi içinde barındırdığı âşık okullarının etkili olduğu, böylece Hatay’ı ozanlık geleneğinin en güçlü illerinden biri haline getirdiği belirgin bir biçimde görülecektir.

\section{Kaynaklar}

Arat, R.R. (1986). Eski Türk şiiri. Ankara: Türk Tarih Kurumu.

Atsız, N. (1992). Türk edebiyatı tarihi. İstanbul: Baysan.

Bahadır, S. (2016). Ceylanlı köyü türküleri. Ankara: Sonçağ.

Başgöz, İ. (1977). Karacaoğlan. İstanbul: Cem.

Başgöz, İ. (1968). İzahlı Türk halk edebiyatı antolojisi. İstanbul: Ararat.

Ekmekçi, M. (2006). Yaşayan Çukurovalı âşıklar ve geleneğe tabi halk şairleri antolojisi. Adana: Adana Kültür Turizm Müdürlügü.

Elçin, Ş. (1988). Akdeniz'de ve Cezayir'de Türk halk şairleri. (ss. 280). Ankara: Türk Kültürünü Araştırma Enstitüsü.

Ergin, M. (2009). Dede Korkut Kitabı-I. Ankara: Türk Dil Kurumu.

Ergun, S.N. (1948). Karacaoğlan. (21. bs.) İstanbul: Maarif Kitaphanesi.

Evliya Çelebi (1982). Seyahatnâme (Hatay-Suriye-Lübnan-Filistin). (İ. Parmaksızoğlu, Haz.). Ankara: Kültür ve Turizm Bakanlığı.

Helmut de Boor (1981). Tarihte, efsanede ve kahramanlık destanlarında Attila. (Y. Önen, Çev.). Ankara: Türk Tarih Kurumu. 
Karaer, M.N. (1980). Karacaoğlan. İstanbul: Tercüman 1001 Temel Eser.

Konyalı, İ.H. (t.y.). Sefil Molla divanı. Antakya.

Köprülü, F. (1986). Edebiyat araştırmaları. Ankara: Türk Tarih Kurumu.

Köprülü, M. F. (1980), Türk edebiyatı tarihi. İstanbul: Ötüken.

Sakaoğlu, S. (2004). Karacaoğlan. Ankara: Akçağ.

Sakaoğlu, S.- Duymaz, A. (2002). İslamiyet öncesi Türk destanlarl. İstanbul: Ötüken.

Türkan, H. K.(2017). Asşk Duran Bebek. Konya: Kömen.

Yakıcı, A. (2009). Ozan dili çevik olur/ Âşık edebiyatı yazıları. Ankara: Gazi.

Yakıcı, A. (2005). Yahya Şükrü Lelik-Ceylanıma selam söyle. Ankara: Tisav.

Yalman, A.R. (1977). Cenupta Türkmen oymakları I. Ankara: Kültür Bakanlığı.

Yıldırım, D. (1998). Türk bitiği. Ankara: Akçăg. 